\title{
Cytokinin Differences in In Vitro Cultures and Inflorescences from Normal and Mantled Oil Palm (Elaeis guineensis Jacq.)
}

\author{
Siew-Eng Ooi • Ondřej Novák · Karel Doležal • \\ Zamzuri Ishak $\cdot$ Meilina Ong-Abdullah
}

Received: 26 December 2012/ Accepted: 7 May 2013/Published online: 5 July 2013

(C) The Author(s) 2013. This article is published with open access at Springerlink.com

\begin{abstract}
The mantled abnormality phenotype of the oil palm affects fruit development and thus jeopardizes oil yield. Cytokinins have been implicated in the development of the mantled phenotype. Endogenous cytokinin levels in the normal and mantled phenotypes were compared to determine whether levels of specific cytokinins are associated with mantling. Endogenous cytokinins were identified and quantified in in vitro cultures and inflorescences from normal and mantled oil palms. Twenty-two isoprenoid cytokinins, comprising the zeatin, dihydrozeatin, and isopentenyladenine types, were quantified. Total cytokinin levels, particularly of trans-zeatin and isopentenyladenine types, increased during the in vitro culture process, with the highest levels detected at the proliferating polyembryoid stages. The cytokinins were present mainly in their inactive 9-glucoside forms during in vitro culture. On the other hand, the predominant trans-zeatin cytokinins in inflorescences were present mainly in their ribotide forms,
\end{abstract}

Electronic supplementary material The online version of this article (doi:10.1007/s00344-013-9352-6) contains supplementary material, which is available to authorized users.

S.-E. Ooi $(\bowtie) \cdot$ Z. Ishak $\cdot$ M. Ong-Abdullah

Advanced Biotechnology and Breeding Centre, Malaysian Palm Oil Board, 6 Persiaran Institusi, Bandar Baru Bangi,

43000 Kajang, Selangor, Malaysia

e-mail: oseng@mpob.gov.my

O. Novák $\cdot$ K. Doležal

Laboratory of Growth Regulators, Palacký University and Institute of Experimental Botany ASCR, Šlechtitelů 11,

78371 Olomouc, Czech Republic

O. Novák · K. Doležal

Centre of the Region Haná for Biotechnological and Agricultural Research, Faculty of Science, Palacký University, Šlechtitelů 11, 78371 Olomouc, Czech Republic suggesting a metabolic pool of cytokinins for conversion to biologically active free bases or ribosides. Levels of specific cytokinins were significantly different in tissues at different stages. Mantled developed inflorescences contained higher levels of isopentenyladenine 9-glucoside compared with normal inflorescences. Mantled-derived callus tissues had higher isopentenyladenine levels but significantly lower levels of trans-zeatin 9-glucoside, dihydrozeatin riboside, and dihydrozeatin riboside $5^{\prime}$-monophosphate cytokinins compared with normal-derived callus. It would be of considerable interest to verify these specific cytokinin differences in more callus cultures and clones.

Keywords Cytokinin - Elaeis guineensis - Inflorescence · In vitro culture $\cdot$ Mantled $\cdot$ Somaclonal variation

\section{Introduction}

Oil palm is one of the world's leading crops for the production of edible vegetable oil. The oil yield from oil palm globally is approximately 3.69 tonnes/hectare ( $\mathrm{t} / \mathrm{ha}$ ), whereas rapeseed, a major temperate oil crop, produces $0.71 \mathrm{t} /$ ha (Mielke 1994). Vegetative propagation of the oil palm through tissue culture is one of the main approaches for production of elite planting material. However, somaclonal variations arising from in vitro propagation are common (Jaligot and others 2011). Although somaclonal variants can be a source of plants with improved characteristics such as flower color variants (Sato and others 2011) or abiotic and biotic stress tolerance, it can also lead to undesirable variants. A somaclonal variant arising from oil palm tissue culture, known as mantled, affects floral and fruit development (Corley and others 1986). The mantled 
phenotype is undetectable until the palm starts to flower and results in partial or total sterility, negatively impacting oil yield (Ho and others 2009; Konan and others 2010).

Plant growth regulators such as cytokinins have been implicated in the development of the mantled variant (Besse and others 1992; Jones 1998; Eeuwens and others 2002; Jaligot and others 2011). Addition of kinetin to the media with low levels of auxin resulted in a high incidence of mantling (Eeuwens and others 2002). The use of cytokinins in polyembryoid culture medium has gradually declined because high exogenous cytokinins increased the incidence of abnormal in vitro phenotypes such as multiple shoot formation and inflorescence-like structures (Paranjothy and others 1995; Tarmizi 1997; Aberlenc-Bertossi and others 1999; Inpeuy and others 2011). In addition, low levels of endogenous zeatin-type cytokinins have been found in fast-growing calli (FGC), a type of callus that gives rise to nearly $100 \%$ mantled palms (Besse and others 1992). However, mantled ramets can still be generated from palms that did not produce FGC, as nodular compact calli, which are produced with current tissue culture practices, can also give rise to abnormal regenerants (Rival and others 2008; Ho and others 2009). Moreover, mantled regenerants were produced from cultures propagated on medium containing only auxin, although the frequency of mantling was much lower than when a medium containing auxin and cytokinin was used (Paranjothy and others 1995).

With the development of more sensitive approaches such as LC-MS/MS to quantify endogenous hormone levels, more studies on the detection and quantitation of cytokinins have been reported in the recent years (Tarkowski and others 2009; Fu and others 2011). LC-MS/MS is widely used because of its high separation ability and high sensitivity and it provides quantitative data on multiple analytes in a single run (Novák and others 2003; Liang and others 2012).

Thus, it would be of considerable interest and value to determine and evaluate whether the levels of specific endogenous cytokinins are associated with the mantling phenotype and to identify at which stages the differences, if any, could be detected. The present study thus aimed to detect and quantify endogenous cytokinin levels in oil palm cultures and reproductive tissues derived from normal and mantled phenotypes.

\section{Materials and Methods}

\section{Plant Material}

Two types of material were sampled in this study: inflorescences and in vitro-cultured tissues. All palms sampled were of the tenera variety. Underdeveloped inflorescences $2 \mathrm{~cm}$ long and developed inflorescences $12-15 \mathrm{~cm}$ long were harvested from two clones, 242 and 247, with each clone comprising one normal and one mantled palm (all palms were 4 years old at time of sampling). The normal and mantled inflorescences were harvested from the plantations of the Malaysian Palm Oil Board (MPOB) and frozen in liquid nitrogen.

The leaf cabbages of two clones, 236 and 247, with each clone comprising one normal and one mantled palm, were subjected to in vitro culture procedures following the protocol described by Rohani and others (2003), with modifications. Briefly, callus initiation was conducted on Murashige and Skoog (MS) media supplemented with $10 \mathrm{mg} / \mathrm{L}$ naphthalene-acetic acid (NAA) only. The callus arose from the cultured leaf explants after approximately 3 months in culture. The callus that was attached to the leaf explants was dissociated from the leaf explants and frozen separately. Subsequently, sporadic embryogenic callus that arose from the callus cultures was transferred to MS media supplemented with $5 \mathrm{mg} / \mathrm{L}$ NAA for proliferation and differentiation into polyembryoids. Subculturing of these polyembryoids into fresh media was conducted at 2-month intervals. The polyembryoids continued to proliferate and generally turned from white to green within $2-4$ months after that and were designated as stage 2 polyembryoids. After that, the stage 2 polyembryoids were subcultured and continued to develop and produced shoots 4-6 months into this polyembryoid proliferation and development phase. Polyembryoids at this stage were designated as stage 3 polyembryoids. Sampling was thereby conducted at the following stages: cultured leaf explants with callus, proliferating polyembryoids at stage 2 (emb-2), and polyembryoids at stage 3 (emb-3) (Fig. 1). The inflorescences of a third clone, 164, also comprising one normal and one mantled palm (both 7 years of age at the time of sampling), were sampled for in vitro culture; callus was produced during the culturing process but failed to develop further into polyembryoids. Hence, only callus samples were collected for this clone. All samples were stored at $-80{ }^{\circ} \mathrm{C}$ and freeze-dried for cytokinin extraction.

\section{Extraction of Cytokinins}

Cytokinin was extracted from approximately $50 \mathrm{mg}$ freezedried tissues as previously described (Novák and others 2008). The extraction was conducted in duplicate as the amount of sample tissue from in vitro culture was limited. There was a need to compromise on the sampling amount because somatic embryogenesis is a sporadic occurrence and there needs to be enough culture remaining to develop further in vitro. The freeze-dried sample was weighed and ground to powder with a 3-mm carbide tungsten bead in a MM301 vibration mill 

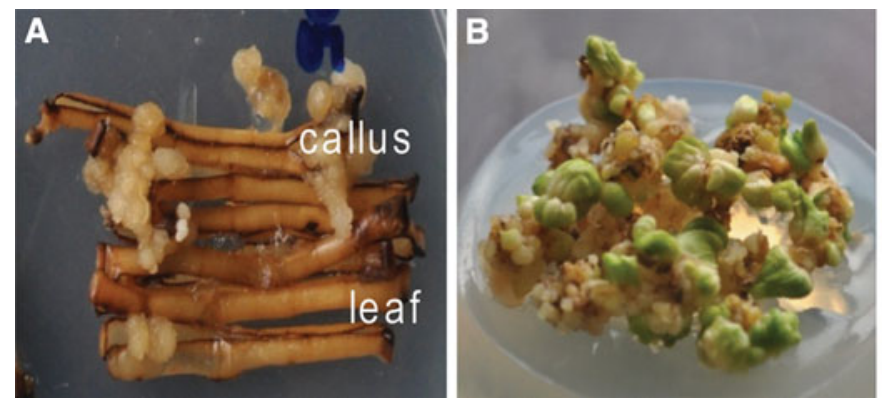

Fig. 1 Stages in in vitro culture and inflorescence development used for cytokinin detection and quantitation. a Leaf explant (leaf) with callus attached. b Stage 2 polyembryoids (emb-2). c Stage 3

(Retsch $\mathrm{GmbH} \& \mathrm{Co}$. KG, Haan, Germany) at a frequency of $27 \mathrm{~Hz}$ for $3 \mathrm{~min}$. The exact weight of the sample was noted. Bieleski extraction buffer (60\% methanol, $25 \%$ chloroform, $5 \%$ formic acid) (Bieleski 1964) was then added at $1 \mathrm{ml}$ per sample; deuterium-labeled internal standards $\left[{ }^{13} \mathrm{C}_{5}\right] \mathrm{tZ},\left[{ }^{2} \mathrm{H}_{5}\right]$ tZR, $\left[{ }^{2} \mathrm{H}_{5}\right] \mathrm{tZ} 9 \mathrm{G}, \quad\left[{ }^{2} \mathrm{H}_{5}\right] \mathrm{tZOG},\left[{ }^{2} \mathrm{H}_{5}\right] \mathrm{tZROG},\left[{ }^{2} \mathrm{H}_{5}\right] \mathrm{tZRMP}$, $\left[{ }^{13} \mathrm{C}_{5}\right] \mathrm{cZ},\left[{ }^{2} \mathrm{H}_{3}\right] \mathrm{DZ},\left[{ }^{2} \mathrm{H}_{3}\right] \mathrm{DZR},\left[{ }^{2} \mathrm{H}_{3}\right] \mathrm{DZ} 9 \mathrm{G},\left[{ }^{2} \mathrm{H}_{7}\right] \mathrm{DZOG}$, $\left[{ }^{2} \mathrm{H}_{3}\right]$ DZRMP, $\left[{ }^{2} \mathrm{H}_{6}\right] \mathrm{iP},\left[{ }^{2} \mathrm{H}_{6}\right] \mathrm{iPR},\left[{ }^{2} \mathrm{H}_{6}\right] \mathrm{iP} 9 \mathrm{G},\left[{ }^{2} \mathrm{H}_{6}\right] \mathrm{iPRMP}$, $\left[{ }^{2} \mathrm{H}_{7}\right] \mathrm{BA},\left[{ }^{2} \mathrm{H}_{7}\right] \mathrm{BAR},\left[{ }^{2} \mathrm{H}_{7}\right] \mathrm{BA} 9 \mathrm{G},\left[{ }^{2} \mathrm{H}_{7}\right] \mathrm{BARMP},\left[{ }^{15} \mathrm{~N}_{4}\right] \mathrm{mT}$, and $\left[{ }^{15} \mathrm{~N}_{4}\right]$ oT were also added (Tarkowski and others 2006; Novák and others 2008). The subsequent solid-phase extraction and immunoaffinity purification steps are as described previously by Tarkowski and others (2006) and Novák and others (2008).

\section{Detection and Quantification of Cytokinins}

The extracted and purified cytokinin samples were dissolved in $1 \%$ formic acid and subjected to UPLC-MS/MS. UPLC-ESI(+)-MS/MS was conducted using the Acquity UPLC $^{\mathrm{TM}}$ System (Waters, Milford, MA, USA) together with a Binary solvent manager, Sample manager, and 2996 PDA detector, combined with a Micromass Quattro micro ${ }^{\text {TM }}$ API (Waters MS Technologies, Manchester, UK) at the Laboratory of Growth Regulators, Palacký University and Institute of Experimental Botany ASCR, Czech Republic (Novák and others 2008). Data were processed using MassLynx ${ }^{\mathrm{TM}}$ software with the QuanLynx ${ }^{\mathrm{TM}}$ and QuantOptimize $^{\mathrm{TM}}$ programs ver. 4.0 (Waters). The limit of detection (LOD) for the assay was $0.05-0.1$ fmol.

\section{Statistical Analysis}

Data were subjected to one-way ANOVA using Mini$\operatorname{tab}^{\circledR} 15$ statistical software (Minitab, Inc., State College, PA, USA). The variance was analyzed by Tukey's significant difference, with the level of significance set to $P<0.05$ or $P<0.01$. For analysis purposes, concentrations below quantifiable levels were set as zeros.
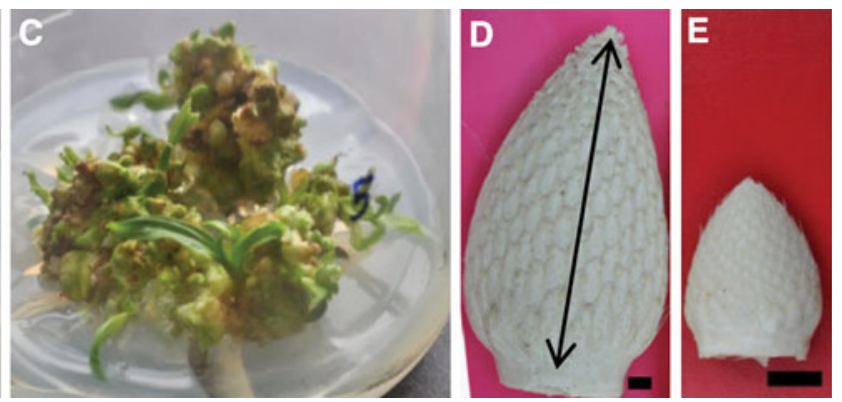

polyembryoids (emb-3). d Developed inflorescence (12-cm length indicated by arrow). e Underdeveloped inflorescence $(2 \mathrm{~cm})$. Scale bar $1 \mathrm{~cm}$

Significant differences between normal and mantled groups are indicated in the figures.

\section{Results}

Tissue culture from one of the clonal sets ended after the callusing stage as it did not generate polyembryoids. Hence, most of the analyses were conducted based on two clones, except for the callusing stage, where results from three clones were used. In all oil palm samples, only the isoprenoid class of cytokinins was detected. Aromatic cytokinins such as benzyladenine and topolins were undetected in 50-60 mg of freeze-dried samples, suggesting that their levels were lower than the LOD of the assay. The exception was in one of the callus samples, which contained very low amounts of topolins: $0.76 \pm 0.01 \mathrm{pmol}$ ortho-topolin/g dry weight (DW) and $13.64 \pm 0.71 \mathrm{pmol}$ ortho-topolin riboside/g DW. Thus, in this study, analysis was focused on the different types and forms of isoprenoid cytokinins and their levels across development in mainly two clones.

\section{Predominant Cytokinins in Inflorescences}

Trans-zeatins (tZ) were the predominant cytokinins in both underdeveloped and developed inflorescences (Supplementary Tables 1-4; Fig. 2a) and were present mainly in ribotide form. The other cytokinins were also present largely in their ribotide forms (Fig. 2b). In addition, the proportion of each cytokinin form was consistent in both palms only at the developed inflorescence stage (Fig. 2b).

In mantled palms, the level of total cytokinins was higher in underdeveloped than developed inflorescences, but the reverse was observed in normal palms (Fig. 3). At the developed stage itself, the level of total cytokinins was lower in mantled than in normal inflorescences of the respective clone. In addition, levels of the predominant $\mathrm{tZ}$ cytokinins were lower in developed inflorescences from 
Fig. 2 Cytokinin (CK) levels and distribution in underdeveloped and developed inflorescences of normal palms (clones 242 and 247). a Levels of the four cytokinin types. Each group of cytokinins comprises the respective free base, riboside, $O$-glucoside, riboside- $O$-glucoside, 9 -glucoside, and ribotide forms. Values are mean $\pm \operatorname{SD}(n=2)$ b Distribution of cytokinin forms. 9-Glucosides $\mathrm{tZ9G}$, cZ9G, DZ9G, iP9G; $O$ glucosides $\mathrm{tZOG}$, tZROG, cZOG, cZROG, DZOG, DZROG; ribotides tZRMP, cZRMP, DZRMP, iPRMP; ribosides $\mathrm{tZR}, \mathrm{cZR}, \mathrm{DZR}$, $\mathrm{PRR}$; free $C K s \mathrm{tZ}, \mathrm{cZ}, \mathrm{DZ}, \mathrm{iP}$
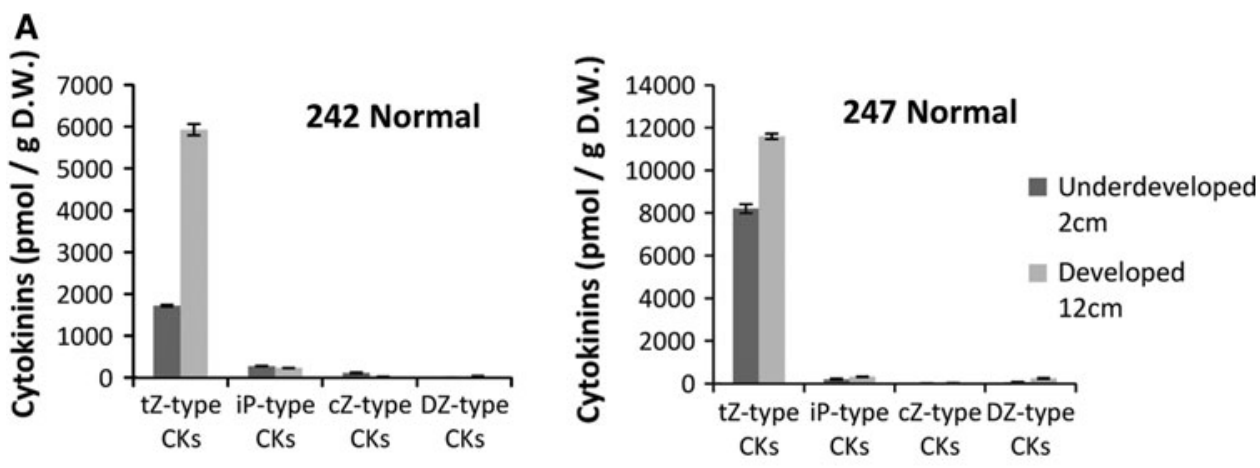

mantled (1,276-1,303 pmol/g DW) than from normal palms (5,931-11,592 pmol/g DW) (Supplementary Tables 1-4). Another notable observation was that the majority of dihydrozeatin (DZ) cytokinins were 6-40-fold lower in mantled than in normal developed inflorescences of clone 242 and were 25-33-fold lower for clone 247 (Fig. 4).

As for the different cytokinin forms, ribotides represented a larger fraction in developed mantled inflorescences from both clones than in normal inflorescences (Fig. 5a). Conversely, the proportion of 9-glucosides in developed mantled inflorescences was distinctly lower. An exception was seen only in the levels of iP 9-glucoside,

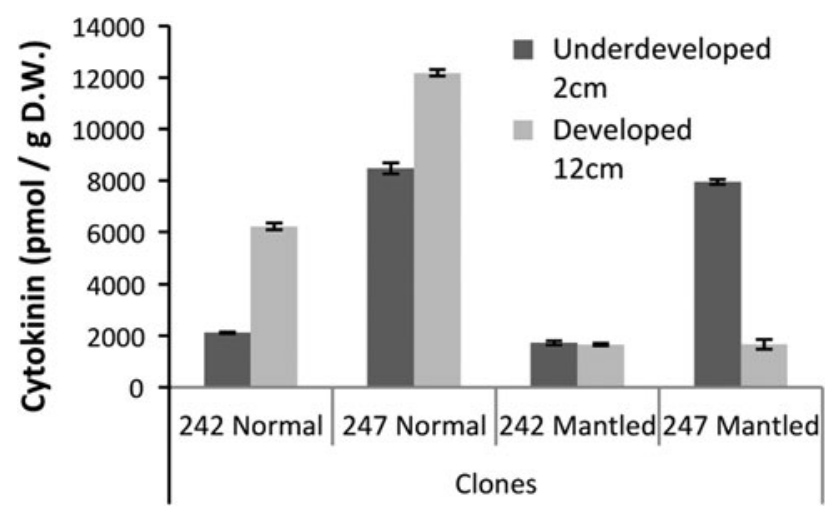

Fig. 3 Levels of total cytokinins in underdeveloped compared with developed inflorescences from normal and mantled palms of clones 242 and 247. Values are mean $\pm \operatorname{SD}(n=2)$ which was significantly higher in the developed mantled inflorescences compared with the normal inflorescences (Fig. 5b).

\section{Predominant Cytokinins in In Vitro Cultures}

Total cytokinin content was lower in in vitro culture stages than in inflorescences (Supplementary Tables 1-4). Cytokinin content was highest at the polyembryoid proliferation stage among the in vitro culture stages analyzed. Even then, the highest total cytokinin content in vitro, that is, at the polyembryoid proliferation stage of the normal palm of clone 247 , was only $2,949 \pm 346 \mathrm{pmol} / \mathrm{g}$ DW compared to that in developed inflorescences, which reached up to $12,178 \pm 126 \mathrm{pmol} / \mathrm{g}$ DW (Supplementary Table 4).

During tissue culture, levels of each cytokinin type increased with in vitro progression. Leaf explant cultures contained the lowest amount of cytokinins compared with the other culture stages (Fig. 6a). Among the in vitro culture stages, isopentenyladenine (iP) and $\mathrm{tZ}$ cytokinins were predominant (Fig. 6a). Cytokinins were present mainly in their 9-glucoside form, whereas the proportion of free bases was highest in the leaf explant cultures (Fig. 6b). For clone 247 , the proportion of 9-glucosides gradually decreased from callus to the polyembryoid stages, whereas the proportion of ribotides, $O$-glucosides, and free bases increased. This pattern was not clearly exhibited by clone 236 .

Among the cytokinins quantified, levels of iP 9-glucoside were the highest in in vitro culture samples 
Fig. 4 Dihydrozeatin cytokinin levels are higher in developed inflorescences of normal compared with mantled phenotypes, within the individual clones (242 and 247). Values are mean $\pm \mathrm{SD}(n=2)$. Significant differences at $* P \leq 0.05$ or $* * P \leq 0.01$
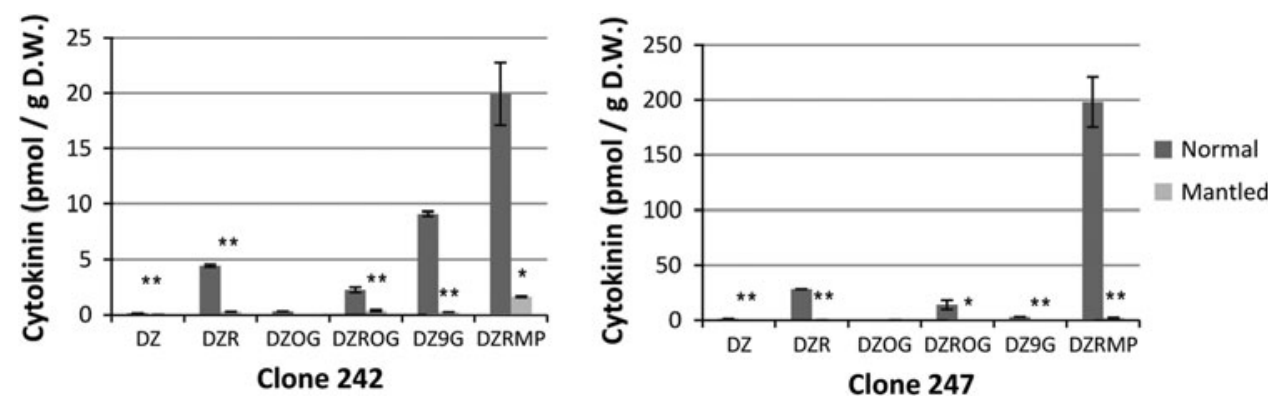

B

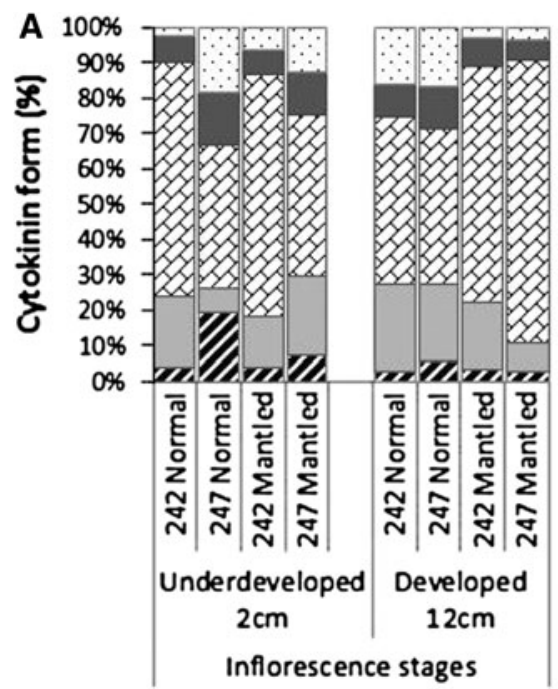

$\checkmark$ 9-glucosides

O-glucosides

$\triangle$ Ribotides

$\square$ Ribosides

a Free CKs

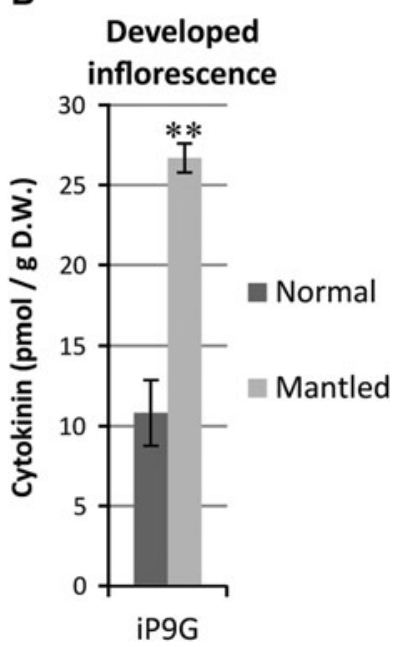

cZROG, DZOG, DZROG; ribotides tZRMP, cZRMP, DZRMP, iPRMP; ribosides tZR, cZR, DZR, iPR; free $C K s$ tZ, cZ, DZ, iP. b iP9G level in developed inflorescences from normal and mantled phenotypes (both clones). Values are mean $\pm \operatorname{SD}(n=2)$. Significant differences at $* * P \leq 0.01$

environmental influences, or other unknown factors. However, we analyzed the data for consistencies in cytokinin levels in the two clones (three clones for the callus stage) for statistically significant differences between the normal and mantled phenotypes.

Levels of DZ riboside, DZ riboside-5'-monophosphate, and tZ 9-glucoside cytokinins were significantly higher in callus derived from normal palms than that from mantled palms (Fig. 8). The highest fold difference between normal and mantled-derived callus was observed in tZ 9-glucoside level, which was approximately 5.2-fold higher in callus from normal palms. In contrast, levels of free iP cytokinins were lower in callus of normal palms than that in mantled palms (Fig. 8). At the stage 3 polyembryoids, only levels of free DZ cytokinins were significantly higher in normal than in the mantled groups, although the amounts were very low (Fig. 8). 

distribution in in vitro cultures of normal palms (clones 236 and 247). a Levels of cytokinin types. Each group of cytokinins comprises the respective free base, riboside, $O$-glucoside, riboside- $O$-glucoside,

9-glucoside, and ribotide forms.

Values are mean $\pm \operatorname{SD}(n=2)$.

b Distribution of cytokinin forms. 9-Glucosides $\mathrm{tZ9G}$, glucosides $\mathrm{tZOG}$, tZROG, cZOG, cZROG, DZOG, DZROG; ribotides tZRMP, cZRMP, DZRMP, iPRMP; ribosides $\mathrm{tZR}, \mathrm{cZR}, \mathrm{DZR}$, $\mathrm{PPR}$; free $C K s \mathrm{tZ}, \mathrm{cZ}, \mathrm{DZ}, \mathrm{iP}$
Fig. 6 Cytokinin levels and cZ9G, DZ9G, iP9G; $O$ -
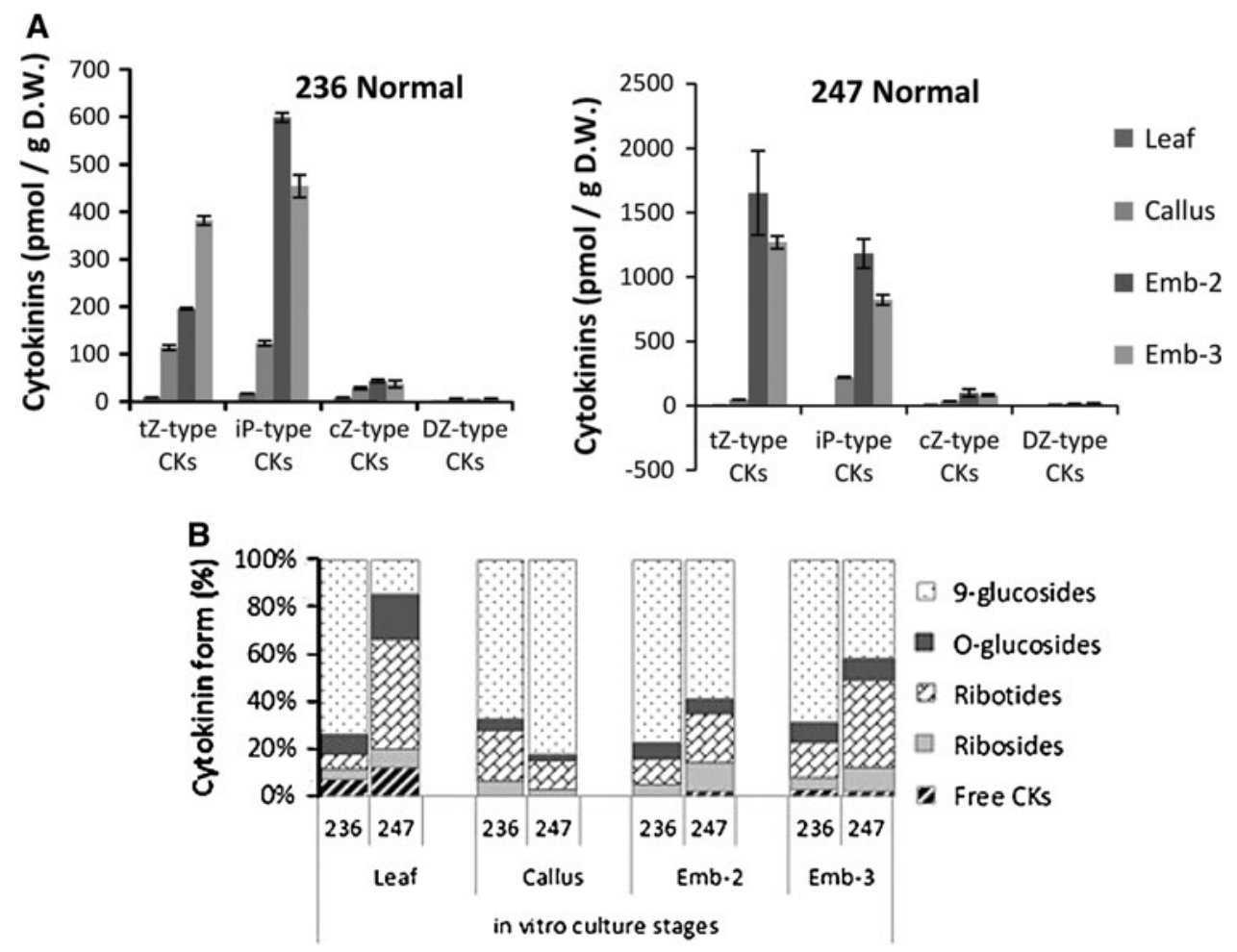

Fig. 7 Comparison in the distribution of cytokinin forms (\%) in in vitro culture stages from normal and mantled palms (clones 236 and 247).

9-Glucosides $\mathrm{tZ9G}$, cZ9G, DZ9G, iP9G; O-glucosides tZOG, tZROG, cZOG, cZROG, DZOG, DZROG; ribotides tZRMP, cZRMP, DZRMP, iPRMP; ribosides $\mathrm{tZR}$, cZR, DZR, iPR; free CKs: tZ, cZ, DZ, iP

Fig. 8 Differences in levels of various cytokinins at specific in vitro culture stages, callus $(n=3)$, and stage 3

polyembryoids $(n=2)$ from normal and mantled phenotypes.

Values are mean $\pm \mathrm{SD}$.

Significant differences at $* P \leq 0.05$ or $* * P \leq 0.01$

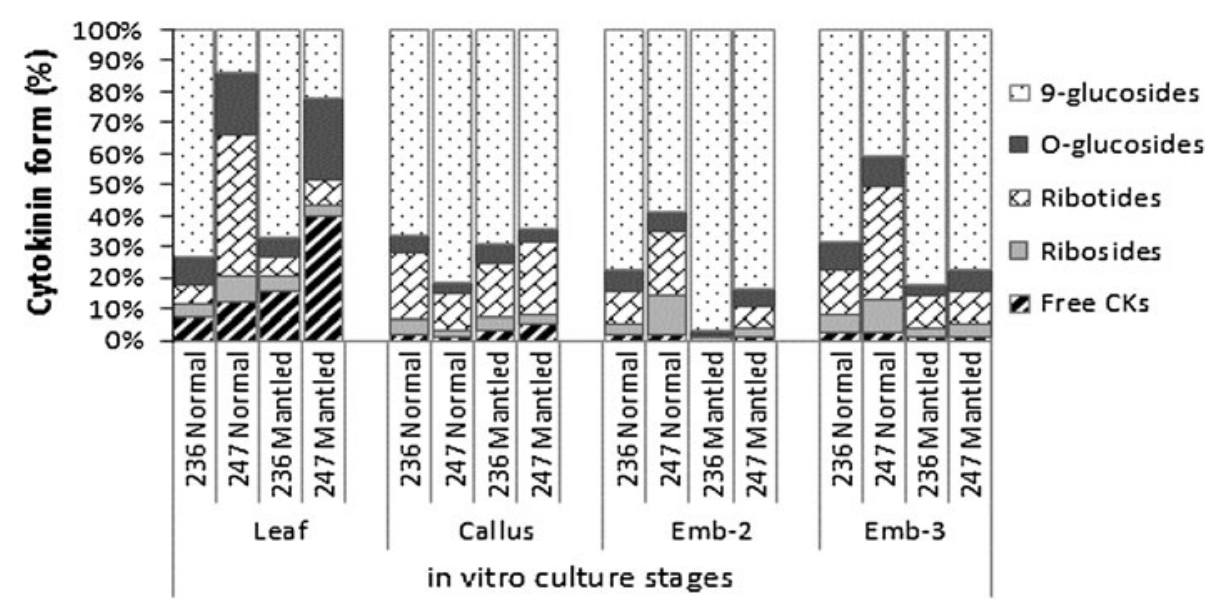

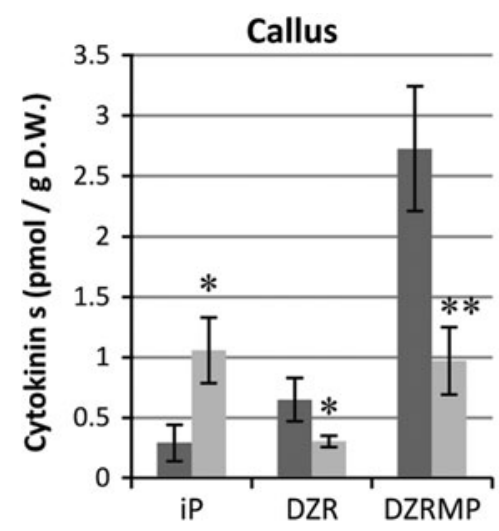
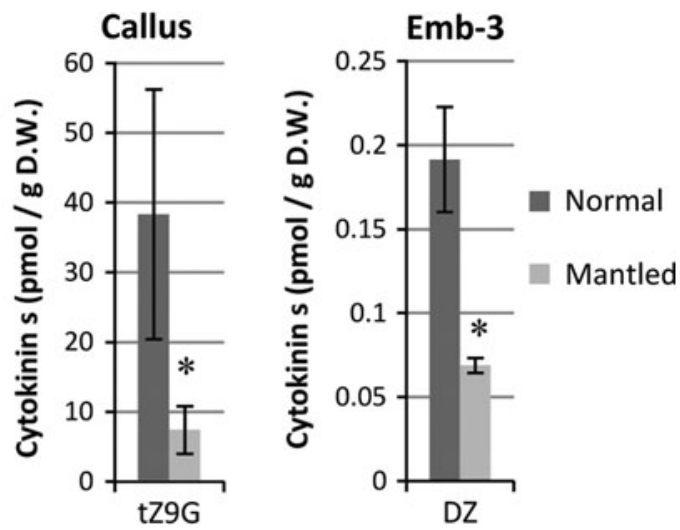


\section{Discussion}

The main cytokinin types can differ across plant species and tissues, and even physiological states (Moncaleán and others 2002; Sakakibara 2006; Frebort and others 2011). In potato, rice, and seeds of oats and lucerne, for example, ciszeatin (cZ) is the dominant cytokinin species, whereas in maize seeds, the DZ-type is predominant (Takagi and others 1985; Suttle and Banowetz 2000; Veach and others 2003; Vyroubalova and others 2009; Stirk and others 2012). The present study found that $t Z s$ and iPs were the predominant cytokinins in in vitro oil palm cultures, whereas in inflorescences, only $\mathrm{tZ}$ cytokinins were predominant. Free bases and ribosides of both $\mathrm{tZ}$ and $\mathrm{iP}$ cytokinins are the preferred substrates for the cytokinin degradation enzyme cytokinin dehydrogenase CKX (Bilyeu and others 2001; Galuszka and others 2004; Stirk and others 2012). cZ is less amenable and DZ and the aromatic cytokinins are resistant to CKX (Schmülling 2004; Tomaz and Marina 2010). Thus, the main cytokinin types of $\mathrm{tZ}$ and iP in these oil palm tissues suggest that this may allow for cells to rapidly control cytokinin activity during in vitro culture and floral development, possibly by the fast turnover of these cytokinins.

Although aromatic cytokinins were generally not detected in this study, cytokinins such as BAP, oT, mT, and their corresponding ribosides and 7-glucosides have been found previously in oil palm tissues such as older inflorescences, embryoids, shoots of seedlings, and ramets using a different extraction method and different HPLC/ELISA detection method (Jones and others 1996). Very low amounts of aromatic BAP cytokinin were also found in the sap exudate of oil palm inflorescences (Huntley and others 2002). It is possible that the extraction method used in this study may not be optimal for the detection of aromatic cytokinins in oil palm although it had been successfully used for other plants (Novák and others 2003; Tarkowski and others 2006; Novák and others 2008).

\section{IP, tZ Cytokinins Were Predominant and Present}

Mainly as Ribotides in Inflorescences

and as 9-Glucosides in In Vitro Cultures

In this study, developing inflorescences had higher cytokinin levels than in vitro cultures, particularly $\mathrm{tZ}$ cytokinins. The tZ-type of cytokinins was also predominant in Arabidopsis inflorescences (Bartrina and others 2011) and in the buds of a gymnosperm species such as Pinus radiata (Montalbán and others 2013). The ribotide was the main form of $\mathrm{tZ}$ and other cytokinins in oil palm inflorescences. It is an inactive form but is a precursor to the active riboside and free base forms in the cytokinin biosynthesis pathway (Sakakibara 2006; Kurakawa and others 2007;
Spíchal 2012). Thus, it appears that oil palm inflorescences contain a metabolic pool of cytokinin ribotides for conversion to active cytokinins when required.

In oil palm in vitro cultures, both $\mathrm{iP}$ and $\mathrm{tZ}$ cytokinins were predominant, suggesting that these cytokinins contribute mainly to the cytokinin activity in these cells. Both $\mathrm{tZ}$ and iP are similarly recognized by the His kinase receptor CRE1/AHK4 in Arabidopsis (Spíchal and others 2004; Romanov and others 2006); this receptor is essential for root growth and normal cell division during embryonic vascular formation (Mahonen and others 2006).

Previously, iP 9-glucoside and zeatin 9-glucoside were the predominant cytokinins found in callus cultures of oil palm (Jones and others 1995) and coconut (Saenz and others 2010). This suggests that the $\mathrm{iP}$ and $\mathrm{tZ}$ cytokinins are predominant during in vitro development of both palm species. We similarly observed that although the inactive iP 9-glucoside was the most abundant in oil palm in vitro cultures, levels of $\mathrm{tZ}$ free base, not iP free base, were the highest among the biologically active free base cytokinins. This suggests that the iP free cytokinins may have undergone 9-glycosylation for inactivation (Kaminek and others 1997; Mok and Mok 2001), and it is the $\mathrm{tZ}$ free cytokinin that probably plays a major role in cytokinin activity during in vitro culture. The 9-glucosides are considered to be inactive cytokinins which generally show low activity in bioassays (Spíchal and others 2004).

Total cytokinin levels also gradually increased as oil palm in vitro culturing progressed from the leaf explants through the polyembryoid proliferation stages. This supports previous observations that cytokinin levels increase throughout oil palm in vitro culture, from callus to embryoids and to plantlets (Besse and others 1994). Relatively low cytokinin levels were detected at the callusing stage. Here, auxins are used in the media to stimulate embryogenesis and the auxins may suppress cytokinin biosynthesis at this stage (Müller and Sheen 2008; Moubayidin and others 2009). Addition of the auxin NAA to tobacco callus culture medium was found to decrease total cytokinin content (Zhang and others 1995), whereas at later oil palm polyembryoid proliferation stages, polyembryoids were cultured on reduced-auxin-supplemented media and this would thus allow de novo biosynthesis of cytokinins, which aids in shoot development (Schmülling 2004). However, even though endogenous cytokinin levels increased overall as the oil palm in vitro cultures developed, the majority were in their inactive and irreversible 9-glucoside forms, similar to previous observations (Jones 1990). The 9-glucosides are also the predominant cytokinin form subjected to degradation by CKX (Galuszka and others 2007) as a detoxification mechanism (Hou and others 2004). It is possible that this also prevents the accumulation of biologically active cytokinins in the cells. 
Accordingly, the probable reduction in cytokinin activity was also indicated by the lower proportion of biologically active free cytokinins during oil palm in vitro culture.

Mantled Developed Inflorescences Contained a Relatively Higher Proportion of Ribotides and iP9G than Normal Inflorescences

Previous reports on cytokinin levels in oil palm inflorescences were mainly focused on the immature or underdeveloped stages (Besse and others 1992; Jones and others 1995). The developed inflorescences sampled in this study were $12-15 \mathrm{~cm}$ long. Floral organ formation is completed by the time the inflorescence size reaches approximately 13-15 cm (Zaidah 2001). At this later stage, a higher proportion of ribotides and a lower proportion of most 9-glucosides were observed in mantled inflorescences. Some evidence of increased iP 9-glucoside levels was previously reported in tissues from mantled flowers and embryoids that gave rise to abnormal clones compared with normal ones (Besse and others 1992; Duval and others 1995; Jones 1995). Thus, we confirmed the observations of higher iP9G levels in mantled developed inflorescences, whereas levels of $\mathrm{tZ}$ and its forms were lower compared with the levels in normal inflorescences. These differences between mantled and normal inflorescences were not obvious at the underdeveloped stage of $2 \mathrm{~cm}$, whereby emergence of flower primordia occurs (Zaidah 2001). When the inflorescence is approximately $5-7 \mathrm{~cm}$, a halt in development of the stamen primordia in the normal female inflorescence and the development of supernumerary carpels in place of staminodes in the mantled female inflorescence occur (Zaidah 2001; Adam and others 2005). Hence, the higher levels of endogenous iP9G cytokinin displayed in mantled developed inflorescences ensued the formation of the mantled floral parts.

The development of supernumerary carpels in mantled female flowers of the oil palm has been deemed a feminization of the male floral organs (Rival and others 2008). In tobacco plants overexpressing the SUPERMAN gene, the sepal converts to petal-like tissues and the petals assume carpel tissue identities (Nibau and others 2011), a phenotype similar to the oil palm mantled phenotype (Jaligot and others 2011; Adam and others 2005). The SUPERMANoverexpressing phenotype was also manifested in wild-type tobacco by exogenous cytokinins, suggesting a feminizing role for cytokinin (Nibau and others 2011). The feminizing role of cytokinins has been reported in other plants such as pine (Kong and others 2012), Mercurialis annua (Durand and Durand 1991), and Blechnum spicant (Menendez and others 2009).

On the other hand, the accumulation of $\mathrm{tZ}$ cytokinins in normal versus mantled developed inflorescences suggests that a lack of $\mathrm{tZ}$ cytokinins in the latter could be associated with the development of the mantling phenotype. With the exception of iP levels that were significantly higher in mantled-derived callus, lower levels of most cytokinins were observed in mantled- compared with the normalderived callus. It has also been previously reported that low levels of cytokinins in proliferating oil palm calli might correlate with abnormality (Besse and others 1992). In addition, the opr 7 opr 8 maize mutant, which produced feminized tassels due to a deficiency in jasmonic acid production, also produced lower levels of cZR cytokinins compared to wild-type plants (Yan and others 2012).

In conclusion, results from this study generally corroborate the previous observations on cytokinins quantified in oil palm in vitro cultures, normal and mantled inflorescences. Oil palm inflorescences generally contained a higher proportion of ribotides, whereas in vitro cultures contained mainly the 9-glucoside cytokinin forms, reflecting the varied role and activity of cytokinins in these different developmental stages of oil palm growth. Although overall cytokinin levels were lower in mantled developed inflorescences or mantled-derived callus compared to their normal counterparts, specific cytokinin types and forms that may be associated with the mantling abnormality were identified. In particular, the increased levels of the iP-type and the lack of tZ-type of cytokinins appear to be implicated in this floral abnormality. Of notable interest is the $\mathrm{tZ}$ 9-glucoside, which was observed at significantly higher levels in calli from normal palms. This cytokinin was in sufficiently high amounts so that it may be detected using simpler methods such as ELISA assays. Levels of $\mathrm{tZ}$ 9-glucoside could then be further verified in in vitro callus cultures that are allowed to regenerate into field-planted palms and then to later corroborate their mantling data.

Acknowledgments We are grateful to the Director-General of the Malaysian Palm Oil Board for permission to publish this study. Our appreciation also goes to Ms. Azizah Mokri, Mr. Roslan Ngadio, Mdm. Norzihan Tahir, and Mr. Zamzuri Ahad from MPOB and Ms. Petra Amakorová from Palacký University and Institute of Experimental Botany for their technical assistance in this study. This project was financially supported by internal funds from the Malaysian Palm Oil Board and the Czech Ministry of Education, Grant No. ED0007/ 01/01 Centre of the Region Haná for Biotechnological and Agricultural Research.

Open Access This article is distributed under the terms of the Creative Commons Attribution License which permits any use, distribution, and reproduction in any medium, provided the original author(s) and the source are credited.

\section{References}

Aberlenc-Bertossi F, Noirot M, Duval Y (1999) BA enhances the germination of oil palm somatic embryos derived from 
embryogenic suspension cultures. Plant Cell Tissue Organ Cult 56:53-57

Adam H, Jouannic S, Escoute J, Duval Y, Verdeil JL, Tregear JW (2005) Reproductive development complexity in the African oil palm (Elaeis guineensis, Arecaceae). Am J Bot 92:1836-1852

Bartrina I, Otto E, Strnad M, Werner T, Schmülling T (2011) Cytokinin regulates the activity of reproductive meristems, flower organ size, ovule formation, and thus seed yield in Arabidopsis thaliana. Plant Cell 23:69-80

Besse I, Verdeil JL, Duval Y, Sotta B, Maldiney R, Miginiac E (1992) Oil palm (Elaeis guineensis Jacq.) clonal fidelity: endogenous cytokinins and indoleacetic acid in embryogenic callus cultures. J Exp Bot 43:983-989

Besse I, Beule T, Verdeil JL, Duval Y (1994) Study of endogenous cytokinin levels associated with an anomaly in floral morphogenesis of Elaeis. In: Teisson E (ed) In vitro culture of tropical plants. CIRAD, Montpellier, pp 37-41

Bieleski RL (1964) The problem of halting enzyme action when extracting plant tissues. Anal Biochem 9:431-442

Bilyeu KD, Cole JL, Laskey JG, Riekhof WR, Esparza TJ, Kramer MD, Morris RO (2001) Molecular and biochemical characterization of a cytokinin oxidase from maize. Plant Physiol 125:378-386

Corley RHV, Lee CH, Law IH, Wong CY (1986) Abnormal flower development in oil palm clones. Planter 62:233-240

Durand B, Durand R (1991) Sex determination and reproductive organ differentiation in Mercurialis. Plant Sci 80:49-65

Duval Y, Besse I, Verdeil JL, Maldiney R (1995) Study on the induction of the floral morphogenesis abnormality in oil palm during the in vitro regeneration process. In: Rao V, Henson IE, Rajanaidu N (eds), Proceedings of the 1993 ISOPB international symposium on recent developments in Oil Palm Tissue Culture and Biotechnology. Kuala Lumpur: Palm Oil Research Institute of Malaysia, pp 64-69

Eeuwens CJ, Lord S, Donough CR, Rao V, Vallejo G, Nelson S (2002) Effects of tissue culture conditions during embryoid multiplication on the incidence of "mantled" flowering in clonally propagated oil palm. Plant Cell Tissue Organ Cult 70:311-323

Frebort I, Kowalska M, Hluska T, Frebortova J, Galuszka P (2011) Evolution of cytokinin biosynthesis and degradation. J Exp Bot 62:2431-2452

Fu J, Sun X, Wang J, Chu J, Yan C (2011) Progress in quantitative analysis of plant hormones. Chin Sci Bull 56:355-366

Galuszka P, Frebortova J, Werner T, Yamada M, Strnad M, Schmülling T, Frebort I (2004) Cytokinin oxidase/dehydrogenase genes in barley and wheat. Eur J Biochem 271:3990-4002

Galuszka P, Popelkova H, Werner T, Frebortova J, Pospisilova H, Mik V, Kollmer I, Schmülling T, Frebort I (2007) Biochemical characterization of cytokinin oxidases/dehydrogenases from Arabidopsis thaliana expressed in Nicotiana tabacum L. J Plant Growth Regul 26:255-267

Ho YW, Tan CC, Soh AC, Wong G, Chong SP, Choo CN, Norazura A (2009) Biotechnological approaches in producing oil palm planting material—a success story. Int J Oil Palm 6:86-93

Hou B, Lim EK, Higgins GS, Bowles DJ (2004) N-glucosylation of cytokinins by glycosyltransferases of Arabidopsis thaliana. J Biol Chem 279:47822-47832

Huntley RP, Jones LH, Hanke DE (2002) Cytokinins and gibberellins in sap exudate of the oil palm. Phytochemistry 60:117-127

Inpeuy K, Chaemalee S, Te-chato S (2011) Cytokinins and coconut water promoted abnormalities in zygotic embryo culture of oil palm. Songklanakarin J Sci Technol 33:653-657

Jaligot E, Adler S, Debladis E, Beule T, Richaud F, Ilbert P, Jean Finnegan E, Rival A (2011) Epigenetic imbalance and the floral developmental abnormality of the in vitro-regenerated oil palm Elaeis guineensis. Ann Bot 108:1453-1462

Jones LH (1990) Endogenous cytokinins in oil palm (Elaeis guineensis Jacq.) callus, embryoids, and regenerant plants measured by radioimmunoassay. Plant Cell Tissue Organ Cult 20:201-209

Jones LH (1995) Clonal propagation of oil palm, past, present and future. In: Rao V, Henson IE, Rajanaidu N (eds), Proceedings of the 1993 ISOPB international symposium on recent developments in Oil Palm Tissue Culture and Biotechnology. Kuala Lumpur: Palm Oil Research Institute of Malaysia, pp 1-20

Jones LH (1998) Metabolism of cytokinins by tissue culture lines of oil palm (Elaeis guineensis Jacq.) producing normal and abnormal flowering palms. J Plant Growth Regul 17:205-214

Jones LH, Hanke DE, Eeuwens CJ (1995) An evaluation of the role of cytokinins in the development of abnormal inflorescences in oil palms (Elaeis guineensis Jacq.) regenerated from tissue culture. J Plant Growth Regul 14:135-142

Jones LH, Martinkova H, Strnad M, Hanke DE (1996) Occurrence of aromatic cytokinins in oil palm (Elaeis guineensis Jacq.). J Plant Growth Regul 15:39-49

Kaminek M, Motyka V, Vankova R (1997) Regulation of cytokinin content in plant cells. Physiol Plant 101:689-700

Konan KE, Durand-Gasselin T, Kouadio YJ, Flori A, Rival A, Duval Y, Pannetier C (2010) In vitro conservation of oil palm somatic embryos for 20 years on a hormone-free culture medium: characteristics of the embryogenic cultures, derived plantlets and adult palms. Plant Cell Rep 29:1-13

Kong L, von Aderkas P, Zaharia I, Abrams SR, Lee T, Woods J (2012) Analysis of phytohormone profiles during male and female cone initiation and early differentiation in long-shoot buds of lodgepole pine. J Plant Growth Regul 31:478-489

Kurakawa T, Ueda N, Maekawa M, Kobayashi K, Kojima M, Nagato Y, Sakakibara H, Kyozuka J (2007) Direct control of shoot meristem activity by a cytokinin-activating enzyme. Nature 445:652-655

Liang Y, Zhu X, Zhao M, Liu H (2012) Sensitive quantification of isoprenoid cytokinins in plants by selective immunoaffinity purification and high performance liquid chromatographyquadrupole-time of flight mass spectrometry. Methods 56: 174-179

Mahonen AP, Bishopp A, Higuchi M, Nieminen KM, Kinoshita K, Tormakangas K, Ikeda Y, Oka A, Kakimoto T, Helariutta Y (2006) Cytokinin signaling and its inhibitor AHP6 regulate cell fate during vascular development. Science 311:94-98

Menendez V, Revilla MA, Fal MA, Fernandez H (2009) The effect of cytokinins on growth and sexual organ development in the gametophyte of Blechnum spicant L. Plant Cell Tissue Organ Cult 96:245-250

Mielke T (ed) (1994) Oil world 2012. ISTA Mielke GmbH, Hamburg, Germany

Mok DW, Mok MC (2001) Cytokinin metabolism and action. Annus Rev Plant Physiol Plant Mol Biol 52:89-118

Moncaleán P, Rodríguez A, Fernández B (2002) Plant growth regulators as putative physiological markers of developmental stage in Prunus persica. J Plant Growth Regul 36:27-29

Montalbán IA, Novák O, Rolčik J, Strnad M, Moncaleán P (2013) Endogenous cytokinin and auxin profiles during in vitro organogenesis from vegetative buds of Pinus radiata adult trees. Physiol Plant 148(2):214-231

Moubayidin L, Di Mambro R, Sabatini S (2009) Cytokinin-auxin crosstalk. Trends Plant Sci 14:557-562

Müller B, Sheen J (2008) Cytokinin and auxin interaction in root stem-cell specification during early embryogenesis. Nature 453:1094-1097 
Nibau C, Di Stilio VS, Wu HM, Cheung AY (2011) Arabidopsis and tobacco SUPERMAN regulate hormone signaling and mediate cell proliferation and differentiation. J Exp Bot 62:949-961

Novák O, Tarkowski P, Tarkowská D, Doležal K, Lenobel R, Strnad M (2003) Quantitative analysis of cytokinins in plants by liquid chromatography/single quadrupole mass spectrometry. Anal Chim Acta 480:207-218

Novák O, Hauserová E, Amakorová P, Doležal K, Strnad M (2008) Cytokinin profiling in plant tissues using ultra-performance liquid chromatography-electrospray tandem mass spectrometry. Phytochemistry 69:2214-2224

Paranjothy K, Rohani O, Tan CC, Wong G, Soh AC (1995) Incidences of abnormalities in relation to in vitro protocols. In: Rao V, Henson IE, Rajanaidu N (eds), Recent development in oil palm tissue culture and biotechnology. PORIM, Selangor, Malaysia, pp 77-85

Rival A, Jaligot E, Beulé T, Finnegan EJ (2008) Isolation and expression analysis of genes encoding MET, CMT, and DRM methyltransferases in oil palm (Elaeis guineensis Jacq.) in relation to the 'mantled' somaclonal variation. J Exp Bot 59:3271-3281

Rohani O, Zamzuri I, Tarmizi AH (2003) Oil palm cloning: MPOB protocol. MPOB Technol No. 26. Malaysian Palm Oil Board, Kuala Lumpur, p 20

Romanov GA, Lomin SN, Schmülling T (2006) Biochemical characteristics and ligand-binding properties of Arabidopsis cytokinin receptor AHK3 compared to CRE1/AHK4 as revealed by a direct binding assay. J Exp Bot 57:4051-4058

Saenz L, Azpeitia A, Oropeza C, Jones LH, Fuchsova K, Spichal L, Strnad M (2010) Endogenous cytokinins in Cocos nucifera L. in in vitro cultures obtained from plumular explants. Plant Cell Rep 29:1227-1234

Sakakibara H (2006) Cytokinins: activity, biosynthesis, and translocation. Annu Rev Plant Biol 57:431-449

Sato M, Kawabe T, Hosokawa M, Tatsuzawa F, Doi M (2011) Tissue culture-induced flower-color changes in Saintpaulia caused by excision of the transposon inserted in the flavonoid $3^{\prime}, 5^{\prime}$ hydroxylase $\left(F 3^{\prime} 5^{\prime} H\right)$ promoter. Plant Cell Rep 30:929-939

Schmülling T (2004) Cytokinin. In: Lennarz W, Lane MD (eds) Encyclopedia of Biological Chemistry. Academic Press, Waltham, MA

Spíchal L (2012) Cytokinins: recent news and views of evolutionally old molecules. Funct Plant Biol 39:267-284

Spíchal L, Rakova NY, Riefler M, Mizuno T, Romanov GA, Strnad M, Schmülling T (2004) Two cytokinin receptors of Arabidopsis thaliana CRE1/AHK4 and AHK3, differ in their ligand specificity in a bacterial assay. Plant Cell Physiol 45:1299-1305

Stirk W, Václavíková K, Novák O, Gajdošová S, Kotland O, Motyka V, Strnad M, van Staden J (2012) Involvement of cis-zeatin, dihydrozeatin, and aromatic cytokinins in germination and seedling establishment of maize, oats and lucerne. J Plant Growth Regul 31:392-405

Suttle JC, Banowetz GM (2000) Changes in cis-zeatin and cis-zeatin riboside levels and biological activity during potato tuber dormancy. Physiol Plant 109:68-74

Takagi M, Yokota T, Murofushi N, Ota Y, Takahashi N (1985) Fluctuation of endogenous cytokinin contents in rice during its life cycle: quantification of cytokinins by selected ion monitoring using deuterium-labelled internal standards. Agric Biol Chem 49:3271-3277

Tarkowski P, Tarkowská D, Novák O, Mihaljević S, Magnus V, Strnad M, Salopek-Sondi B (2006) Cytokinins in the perianth, carpels and developing fruit of Helleborus niger L. J Exp Bot 57:2237-2247

Tarkowski P, Ge L, Yong JWH, Tan SN (2009) Analytical methods for cytokinins. Trends Anal Chem 28:323-335

Tarmizi AH (1997) Assessment of variability in tissue culture-derived buds of oil palm (Elaeis guineensis Jacq.). Ph.D. thesis, University of Liverpool

Tomaz R, Marina D (2010) Cytokinins and their function in developing seeds. Acta Chim Slov 57:617-629

Veach YK, Martin RC, Mok DWS, Malbeck J, Vankova R, Mok MC (2003) O-Glucosylation of cis-zeatin in maize. Characterization of genes, enzymes and endogenous cytokinins. Plant Physiol 131:1374-1380

Vyroubalova S, Vaclavikova K, Tureckova V, Novak O, Smehilova M, Hluska T, Ohnoutkova L, Frebort I, Galuszka P (2009) Characterization of new maize genes putatively involved in cytokinin metabolism and their expression during osmotic stress in relation to cytokinin levels. Plant Physiol 151:433-447

Yan Y, Christensen S, Isakeit T, Engelberth J, Meeley R, Hayward A, Emery RJN, Kolomiets MV (2012) Disruption of OPR7 and $O P R 8$ reveals the versatile functions of jasmonic acid in maize development and defense. Plant Cell 24:1420-1436

Zaidah R (2001) Tissue specific localization of several oil palm genes during flower development. M.Sc. thesis, Universiti Putra Malaysia

Zhang R, Zhang X, Wang J, Letham DS, McKinney SA, Higgins TJV (1995) The effect of auxin on cytokinin levels and metabolism in transgenic tobacco tissue expressing an ipt gene. Planta 196:84-94 